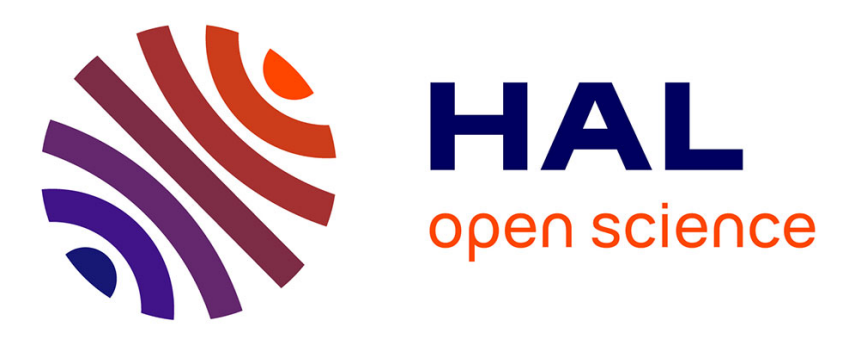

\title{
Dikes of distinct composition intruded into Noachian-aged crust exposed in the walls of Valles Marineris
}

Jessica Flahaut, John F. Mustard, Cathy Quantin, Harold Clenet, Pascal Allemand, Pierre Thomas

\section{To cite this version:}

Jessica Flahaut, John F. Mustard, Cathy Quantin, Harold Clenet, Pascal Allemand, et al.. Dikes of distinct composition intruded into Noachian-aged crust exposed in the walls of Valles Marineris. Geophysical Research Letters, 2011, 38, pp.L15202. 10.1029/2011GL048109 . hal-00659784

\section{HAL Id: hal-00659784 https://hal.science/hal-00659784}

Submitted on 19 Jan 2012

HAL is a multi-disciplinary open access archive for the deposit and dissemination of scientific research documents, whether they are published or not. The documents may come from teaching and research institutions in France or abroad, or from public or private research centers.
L'archive ouverte pluridisciplinaire $\mathbf{H A L}$, est destinée au dépôt et à la diffusion de documents scientifiques de niveau recherche, publiés ou non, émanant des établissements d'enseignement et de recherche français ou étrangers, des laboratoires publics ou privés. 


\title{
Dikes of distinct composition intruded into Noachian-aged crust exposed in the walls of Valles Marineris
}

\author{
Jessica Flahaut, ${ }^{1}$ John F. Mustard, ${ }^{2}$ Cathy Quantin, ${ }^{1}$ Harold Clenet, ${ }^{1}$ Pascal Allemand, ${ }^{1}$ \\ and Pierre Thomas ${ }^{1}$ \\ Received 12 May 2011; revised 27 June 2011; accepted 30 June 2011; published 5 August 2011.
}

[1] Valles Marineris represents the deepest natural incision in the Martian upper crust. Previous studies showed that the upper parts of the walls were made of finely layered probable basalts in most of the chasmata, while the base of the stratigraphy reveals primary Noachian crustal blocks. Exposures of pristine Noachian bedrock are rare on Mars, and mostly observed outside of their geological context. The occurrence of well-preserved and extended outcrops of pristine material in this giant rift could bring valuable information on the early processes that took place at the surface of Mars. Analyses of high resolution data over the best exposures of lower walls in Coprates Chasma, central Valles Marineris, revealed the presence of multiple magmatic intrusions interpreted as dikes. These dikes intrude an old, massive, fractured bedrock interpreted as being preserved ancient Noachian crust. Their composition, determined using CRISM data, and distribution, limited to this ancient crust at the bottom walls, indicate that they might have formed early in the rift formation, and therefore represent exceptionally well-preserved outcrops of the early history of Mars. Citation: Flahaut, J., J. F. Mustard, C. Quantin, H. Clenet, P. Allemand, and P. Thomas (2011), Dikes of distinct composition intruded into Noachian-aged crust exposed in the walls of Valles Marineris, Geophys. Res. Lett., 38, L15202, doi:10.1029/2011GL048109.

\section{Introduction}

[2] Dikes are expected to be present on Mars from their association with volcanic morphologies and surface deformation [Ernst et al., 2001]. Though dikes are rarely exposed on the surface of Mars due to its low erosion rate [Ernst et al., 2001; Pedersen et al., 2010], they can be identified by morphologies representing near-surface manifestations of dike emplacement. Common associated surface morphologies include pit craters, ovoid and linear troughs, shallow grabens, and spatter cones [Mège and Masson, 1996]. Magnetic [McKenzie and Nimmo, 1999] and topographic anomalies [Schultz et al., 2004] could also be potential indicators of buried dikes. Dozens of giant dike swarms have been reported on Mars, with high concentrations in the volcanic areas of Tharsis and Elysium [Carr, 1974; Ernst et al., 2001; Head and Wilson, 2002; Head et al., 2003; Mège et al., 2003]. Recent imaging from the CTX (Context Camera)

\footnotetext{
${ }^{1}$ Laboratoire de Géologie de Lyon, UMR 5276, CNRS, Ecole Normale Supérieure de Lyon, Université Lyon 1, Villeurbanne, France.

${ }^{2}$ Department of Geological Sciences, Brown University, Providence, Rhode Island, USA.

Copyright 2011 by the American Geophysical Union. 0094-8276/11/2011GL048109
}

and HiRISE (High Resolution Imaging Science Experiment) [McEwen et al., 2007] cameras onboard Mars Reconnaissance Orbiter provided the first direct observations of potential eroded and exposed dikes [Korteniemi et al., 2010; Pedersen et al., 2010]. We report here the occurrence of sets of subparallel dikes in the lower walls of Valles Marineris, and the composition of those dikes that were observed with CRISM (the Compact Reconnaissance Imaging Spectrometer for Mars) hyperspectral data [Murchie et al., 2007]. The geologic context for the dikes at the eastern end of Coprates Chasma, which is the main graben system in central Valles Marineris, is shown in Figure 1. Coprates Chasma is 7 to $10 \mathrm{~km}$ in depth, exposing a thick section of the Martian upper crust. Dikes generally intrude a massive, fractured, Low Calcium Pyroxene (LCP)-rich bedrock, which is likely to represent well-preserved exposed primitive Noachian crust [Flahaut et al., 2010a, Pristine Noachian crust and key geologic transitions in the lower walls of Valles Marineris: Insights into early igneous processes on Mars, submitted to Icarus, 2011]. The occurrence of spectrally, and thus compositionally, distinct dikes in the Valles Marineris region has implications for understanding the magmatic processes in this region.

\section{Methods}

[3] Both CRISM and HiRISE observations over the Valles Marineris walls, publicly available as of December 1st, 2010, were investigated to determine the presence and character of meter-scale dike outcrops. Dikes are observed in HiRISE images PSP_007218_1660 (covering the northern walls of Coprates Chasma), PSP_010857_1650 and ESP_013903_1650 (covering the central horst of Coprates Chasma). Only the first of these HiRISE images is associated with a coordinated CRISM observation, identified as FRT00009DB4. Both VNIR and IR detector data were processed using the method described by Murchie et al. [2007] and Flahaut et al. [2010b], to correct for photometric, atmospheric, and noise contributions. Data from the visible and infrared detectors were map-projected then coregistered and integrated to provide spectral data across the full $0-3 \mu \mathrm{m}$ wavelength region [Clenet et al., 2011a]. Summary parameters [Pelkey et al., 2007] were calculated and the LCPINDEX, HCPINDEX, OLINDEX2 were used to search for mafic minerals [Salvatore et al., 2010; Skok et al., 2010].

\section{Results}

[4] Dozens of single ridges were identified within the HiRISE observation PSP_010857_1650, which we interpret 


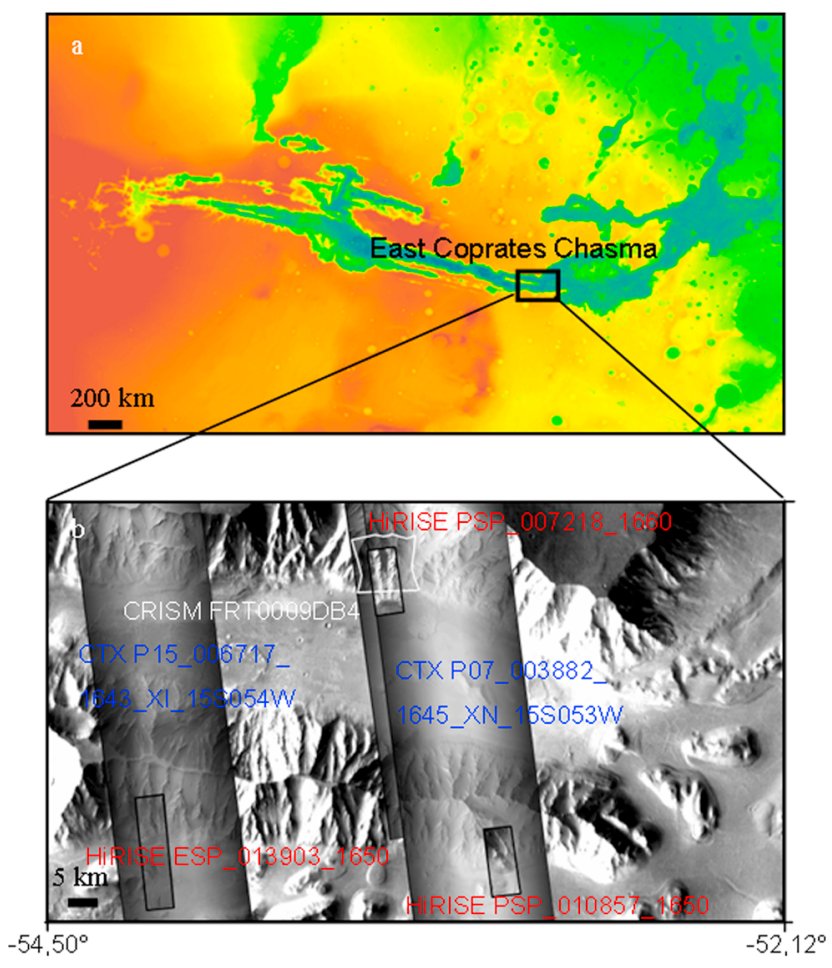

Figure 1. Context of the dike detections. Dikes have been observed in the lower walls of Coprates Chasma, in both the northern walls (HiRISE PSP_007218_1660 and CRISM FRT00009DB4) and the central horst (HiRISE PSP 0108571650 and ESP 013903 1650). (a) Location of the study area on a MOLA elevation map (rainbow scale: low $=$ blue, high $=$ red) of Valles Marineris. The black box indicates the location of Figure 1b. (b) Close-up of the study area. MRO imagery (CTX, HiRISE, CRISM) is projected on a THEMIS Day IR mosaic, used as a $200 \mathrm{~m} /$ pixel background.

to be dikes (Figure 2). The dike segments are sub-parallel to each other and are likely near-vertical, as their apparent orientation is unaffected by topography. We can distinguish at least 2 groups of dikes according to their orientation. The first group is made of a single major dike, roughly striking $\mathrm{N} 112^{\circ}$, approximately $70 \mathrm{~m}$ in width and $600 \mathrm{~m}$ in length. The second group consists of a set of fragmented dikes that strike $\mathrm{N} 85^{\circ}$. The dike segments are emplaced 'en echelon', and are separated by fractures (Figures $2 \mathrm{a}$ and $2 \mathrm{~b}$ ). The dikes appear to be filled with a compositionally distinct material, that is bluer and apparently darker than the surrounding bedrock in the HiRISE color observation (Figures $2 \mathrm{~b}$ and 2c). The dikes can be observed in the CTX imagery as well, but are more difficult to map due to resolution and image quality. When they do outcrop, it is mostly on nearly dust-free spurs. Segments of dikes are approximately $300 \mathrm{~m}$ long in the HiRISE image, with the maximum cumulative dike length estimated to be around $3 \mathrm{~km}$. Widths range from a few meters up to 30 meters for the widest segment. Ridges are also observed at a smaller scale, but it is not clear whether they correspond to fractures, faults, and/or smallerscale dikes (Figure $2 b$ ).

[5] HiRISE observation ESP_013903_1650, also acquired over the central horst of Coprates Chasma, shows a $35 \mathrm{~m}$ wide dike crosscutting a massive bright bedrock. While the bedrock appears bluish on the HiRISE color observation, the dike has a different appearance (Figures $2 \mathrm{~d}$ and $2 \mathrm{e}$ ) which likely reflects a difference in composition. It is approximately $2 \mathrm{~km}$ long and strikes $\mathrm{N} 70^{\circ}$.

[6] A major dike is also observed on HiRISE observation PSP 007218_1660 (Figure 3). This dike is $45 \mathrm{~m}$ wide and at least $7 \mathrm{~km}$ long, with a strike close to $\mathrm{N} 86^{\circ}$ (assuming it is vertical) (Figure 3a). Smaller scale linear features are similarly abundant in the neighborhood of this dike, especially among the outcropping blocks of unaltered Noachian bedrock. At full HiRISE resolution, one cannot determine whether the linear features are dust or cement-filled fractures, or dikes, but they appear darker than the surrounding host bedrock. Figure $3 \mathrm{~b}$ presents a sketch of the observed fractures that are considered as potential small-scale dikes. Figures $3 \mathrm{c}$ and $3 \mathrm{~d}$ are close-ups of the dike, which appears to be filled with large, coarse fragments that are morphologically distinct from the massive, light-toned surrounding bedrock. The area around the dike seems disturbed over an area that is approximately half the dike width, and could be the result of dike-induced dilation [Mastin and Pollard, 1988] or thermal alteration. Dikes in all the images are observed at elevations close to $-3000 \mathrm{~m}$, from MOLA data.

[7] HiRISE observation PSP_007218_1660 is coupled with CRISM observation FRT00009DB4, that can determine the mineralogy of the site. This observation shows a succession of horizontal units with distinct compositions [Flahaut et al., 2010a, submitted manuscript, 2011]. The light-toned and massive material forming the bottom wall bedrock in the HiRISE observation is characterized by broad absorption bands at $0.92 \mu \mathrm{m}$ and $2.0 \mu \mathrm{m}$. This combination of spectral features indicates that Low-Calcium Pyroxene constitutes one of the major components of the bedrock [Mustard et al., 2005; Skok et al., 2009; Clenet et al., 2011b] (Figure 4d). These LCP-rich outcrops are similar in morphology and composition to remnants of the Noachian crust that have been detected elsewhere on Mars (i.e., Isidis Basin

Figure 2. Dike outcrops on HiRISE PSP_010857_1650 (Figures 2a-2c) and HiRISE ESP_013903_1650 (Figures 2d and 2e), which were both acquired over Coprates Chasma central horst. (a) Two sets of dikes have been identified on HiRISE PSP_010857_1650 according to their orientations (white arrows). They outcrop on spurs but tend to be blanketed by dust in between topographic reliefs. The bottom of the observation shows a well-exposed outcrop of bright Noachian bedrock (HiRISE black and white observation). (b) Close-up of Figure 2a, showing that parallel dikes (white arrows) are crosscutted and slightly displaced by smaller fractures (black arrows) that could correspond to minor faults (HiRISE color observation). (c) Close-up of Figure 2b, showing a $30 \mathrm{~m}$ wide dike, that seems filled with a compositionally distinct material, and is surrounded by a darker area that could correspond to induced metamorphism (HiRISE color observation). (d) A major dike (white arrow) is observed among a massive bright bedrock that appears bluish on this HiRISE color observation. (e) Closeup of Figure $2 \mathrm{~d}$, showing a $30 \mathrm{~m}$ wide dike that seems filled with a compositionally distinct material and is surrounded by smaller scale fractures or ridges. 
[Mustard et al., 2009; Skok et al., 2010] and in central peaks of large craters [Quantin et al., 2009, Composition and structure of the subsurface in the vicinity of Valles Marineris as revealed by central uplift of impacts craters, submitted to Icarus, 2011]). Figure 4a is an RGB combination of sum- mary parameters OLINDEX2, LCPINDEX and HCPINDEX. Olivine-rich areas appear in red, while the LCP-rich bedrock appears green. Bluer areas have a higher $\mathrm{HCP}$ content, although the $\mathrm{LCP} /(\mathrm{LCP}+\mathrm{HCP})$ ratio remains high according to the CRISM MGM (Modified Gaussian Model)
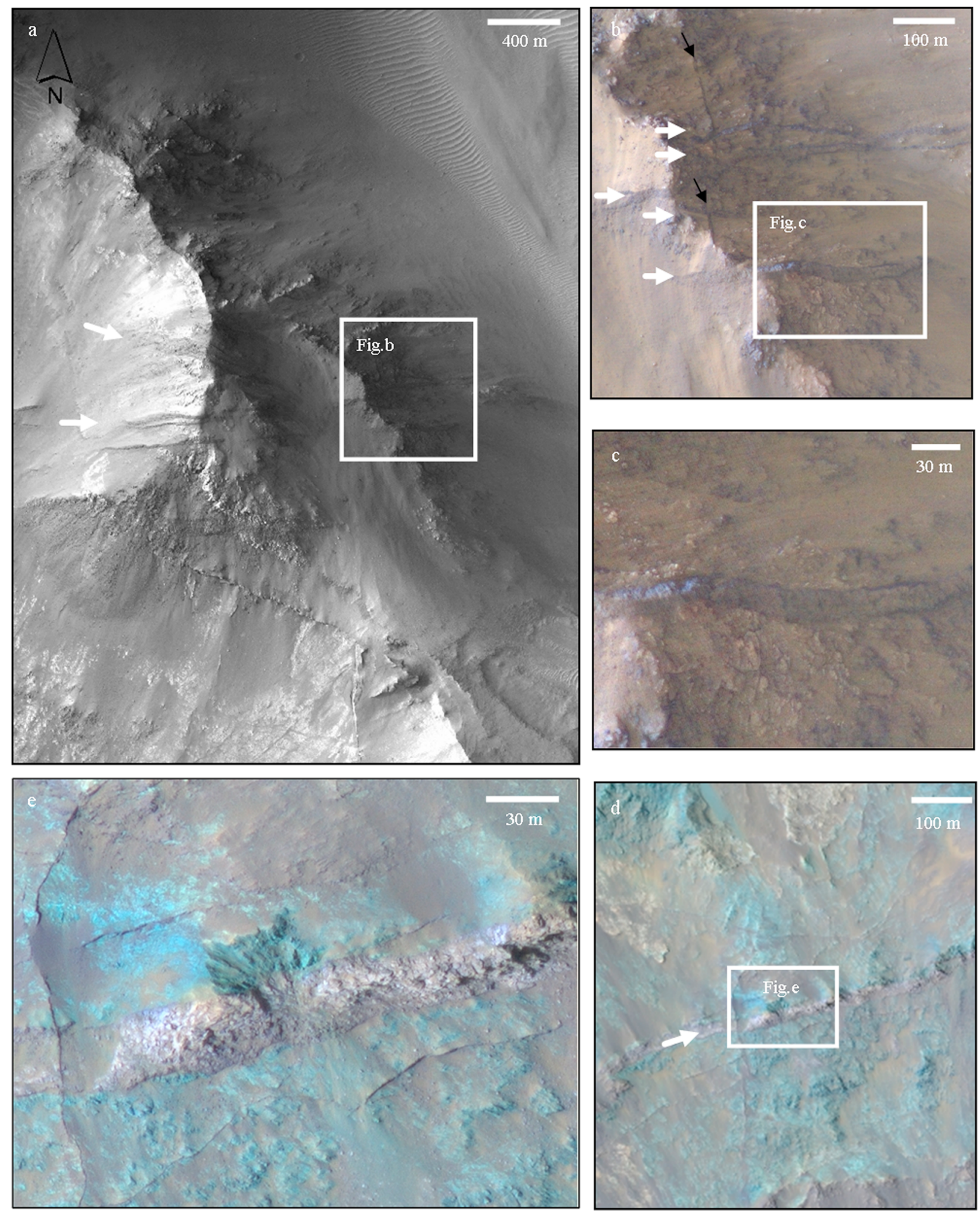

Figure 2 

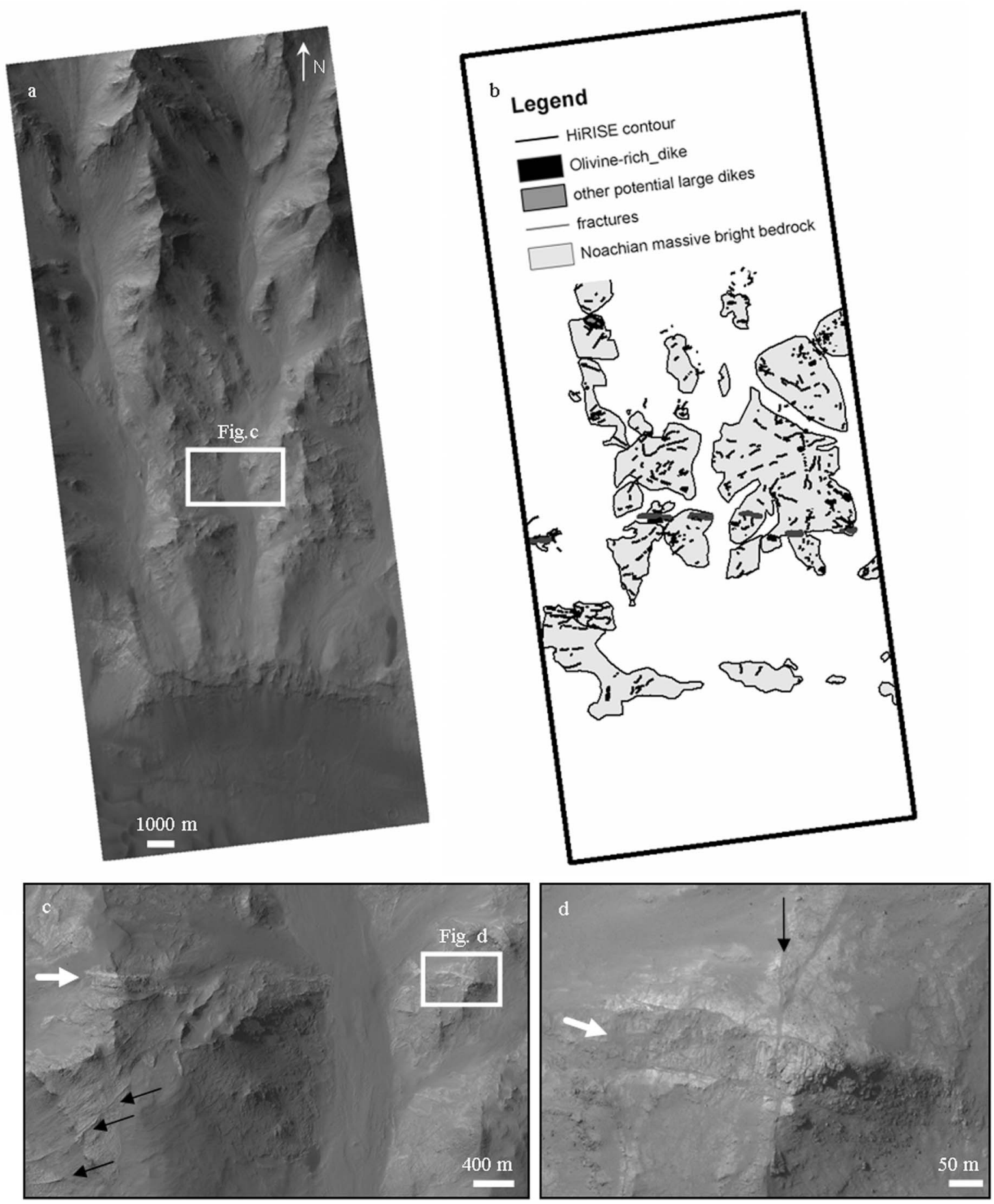

Figure 3. Dike outcrops on HiRISE PSP_007218_1660, which was acquired over the bottom of the northern wall of Coprates Chasma. (a) Full HiRISE scene. The Noachian bedrock can be observed in the middle of the image, where spurs tend to disappear and transition to a massive fractured outcrop. The bottom of the observation shows the canyon floor. (b) Interpretative sketch outlining the main dike, which was analyzed with CRISM (dark gray), the fractures that were considered as potential smaller dikes (thin black line), and the crustal block outcrops (light gray). The dike and fractures are essentially detected among the Noachian crustal blocks. Most of the fractures have an orientation similar to the dike orientation. (c) Close-up of Figure 3a on a segment of the main dike. The white arrow points at the dike while black arrows are highlighting smaller fractures. (d) Close-up of Figure 3c.

[Kanner et al., 2007; Skok et al., 2010] (Figure 4b). This ratio is usually around $60 \%$ in Noachian lava flows, and around $40 \%$ in Hesperian lava flows [Skok et al., 2010]. In observation FRT00009DB4 the ratio value ranges between 40\% (on dusty areas) and $80 \%$ (on clean outcrops), indicating a very high LCP proportion (Figure $4 \mathrm{~b}$ ). The OLINDEX2 parameter strongly highlights a linear feature, a few pixels wide, crosscutting the pyroxene-rich bedrock (Figure 4a). 

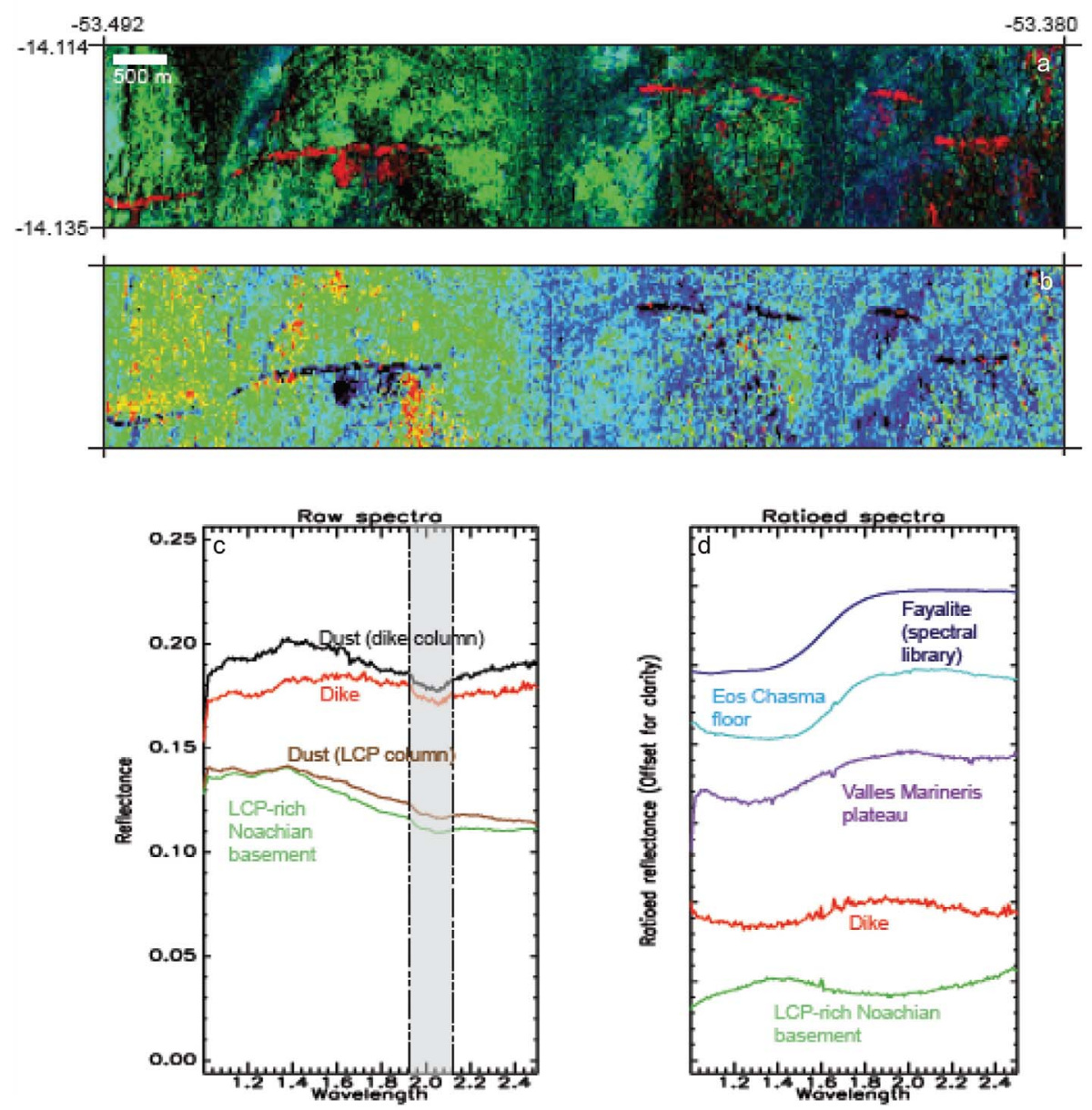

Figure 4. Spectral analysis on CRISM FRT00009DB4 hyperspectral observation. (a) RGB Composition of the dike area R= OLINDEX2 (stretched values: 0-0.028); G = LCPINDEX (stretched values: 0.010-0.114); B = HCPINDEX(stretched values: 0.014-0.344). The dike appears olivine-rich (red), while the surrounding bedrock seems more pyroxene-rich (green and blue). (b) Map of NBDLCP $=($ BDLCP/BDLCP + BDHCP $)$, product of the CRISM MGM, with a rainbow color scale $($ low $=$ blue, high = red; stretched values: $0.398-0.8$ ). The dike area does not show any significant pyroxene content with the MGM, while the surrounding bedrock is generally LCP-rich on dust-free areas. (c) Raw spectra of the dike area at its surrounding bedrock, extracted on the previous CRISM scene. Dust spectra, used for ratioing, were chosen in the same column in the unprojected image. The gray area indicates the area where a residual atmospheric contribution after correction is affecting the spectral signal. (d) Ratioed spectra of the dike and LPC-rich surrounding bedrock (CRISM FRT0009DB4) are compared with CRISM spectra of other olivine-rich detections in the area of Valles Marineris: in the surrounding plateaus (CRISM FRT0000C402) and on the floor of Eos Chasma (CRISM FRT00003B63). Spectra are consistent with fayalite spectra from the CRISM spectral library (the sample C3P059 is shown here for example).

Overlaying this CRISM RGB parameter map on the coupled HiRISE observation confirms that this signature originates from the large dike area and its metamorphosed surroundings. Spectra extracted from this potential olivine-rich area are shown in Figure 4c. Spectra were ratioed over a mean spectrum of dust acquired in a dust-rich area located in the same CRISM column. Spectra from the dike generally show a strong and broad $1.250 \mu \mathrm{m}$ absorption band, which is consistent with olivine. This large band is actually a combination of 3 absorptions centered at 850,1050 and $1250 \mathrm{~nm}$ [Burns, 1970, 1974, 1993]. The shape of the dike spectra is especially consistent with fayalite, or large grain olivinerich basalts [Mustard et al., 2005] (Figure 4d). Nevertheless, this signature has a slight decrease at wavelengths longer than $2.3 \mu \mathrm{m}$ which might be an artifact due to the presence of pyroxene in the dust spectrum that was used to ratio. In the areas adjacent to the dike that we interpret to be metamorphosed, spectra are consistent with an intermediate composition with the spectral signatures of olivine and pyroxene.

\section{Discussion}

[8] Dikes are generally linked with regional tectonics. The orientation of the observed dikes is consistent with the stress regime of Valles Marineris, which is interpreted as being an East-West-oriented set of grabens. We suggest two possible origins for these dikes: 1) they could be linked to graben formation [Mège and Masson, 1996; Mège et al., 2003], or 2) they could have been emplaced after graben formation, and have preferentially propagated through pre-existing fractures and faults. 
[9] On the one hand, dikes have been suggested as a potential mechanism of formation of Valles Marineris, as the inelastic and elastic extension induced by their emplacement could result in graben [Mège and Masson, 1996]. It is widely accepted that the Valles Marineris rifting was formed through extension in the upper crust at the end of the Noachian, resulting in a complex graben system [Mège et al., 2003]. Tharsis is likely to have played a major role in the formation of Valles Marineris, and its important volcanism could reasonably be contemporary with these dikes. This first formation mechanism would explain why dikes are only observed among the primary Noachian bedrock. The dikes would be older with the unit that is stratigraphically above, i.e., the thick Noachian and Hesperian lavas flows, as they do not seem to affect these layers. As these lava flows form most of the wall section in Valles Marineris, the dikes must have been emplaced before the canyon opening. These dikes could then represent a window into the early Martian volcanism and tectonics.

[10] On the other hand, if the vertical dikes reach the upper part of the walls, they would be harder to detect by compositional contrast. Indeed the stack of Noachian and Hesperian lava flows that constitute the upper walls of Valles Marineris are likely to be similar to the dikes in appearance and composition. Moreover, if dikes spread out as potential sills they would remain undetectable, as they would deploy laterally among the horizontal dark layers. Dikes could nevertheless be conduits for magma feeding the flows that formed the horizontal layers at the top of Valles Marineris walls that are interpreted to be volcanic in origin [McEwen et al., 1999].

[11] Olivine has been detected in abundance elsewhere on the surface of Mars. Figure 4d compares spectra of olivine that has been previously reported at different locations on Mars with the olivine detected in the dike. The CRISM ratio spectrum of the dike has a wide bottom-flat absorption centered at long wavelengths, as do most spectra of Martian terrains rich in olivine. This could either mean that these olivine are Fe-rich, or it could be due to an effect of the grain size [Mustard et al., 2005; Poulet et al., 2009; Clenet et al., $2011 \mathrm{~b}$ ]. The dike spectrum could reasonably be that of large grains of olivine-rich basalts, commonly found in terrestrial dikes. This spectrum is also similar to olivine spectra detected elsewhere in the Valles Marineris area, whether this is Hesperian-aged basalts on the top of the Valles Marineris plateau, or the lava flows covering the floor of Eos Chasma [Edwards et al., 2008].

[12] Considering the fact that dikes seem to affect only the pristine Noachian material, which supposedly pre-dates the graben formation, the first formation mechanism is slightly favored. These dikes could have played a significant role in the Valles Marineris system formation; indeed dikes are known to be important factor of continental rifting on Earth [Hauber et al., 2010]. They also bring unique information on the style, intensity and chemical nature of the early Martian volcanism. More dikes are likely to be present in this area, but they are difficult to identify and characterize as the walls have experienced mass wasting, gravity induced slumping, and tectonic erosion. The Noachian bedrock, where dikes are observed, only rarely outcrops, mainly in the deepest troughs of Valles Marineris. Also, high resolution observations, such as provided by HiRISE and CRISM, are required, and their current partial coverage of Valles
Marineris lowers even more the chances to positively identify dikes.

\section{Conclusion}

[13] We positively identified dikes in both HiRISE and CRISM observations in Coprates Chasma in central Valles Marineris. The CRISM observation provides the first clear data showing the composition of Martian dikes and they show strong mafic signatures. These dikes intrude older, Noachian bedrock and have induced dilation in the host rock. They might be related to the magmatic system that lead to the formation of kilometers of dark volcanic layers of the uppermost part of Valles Marineris, whose source has not been clearly identified yet. The orientation of the observed dikes shows that they are definitively connected to the regional tectonics. The occurrence of preserved Noachian bedrock in situ, which is rare on the Martian surface, and compositionally distinct dikes, underlines the need for future Martian exploration in Valles Marineris.

[14] Acknowledgments. This survey was conducted at Brown University and supported by the 'Explora'Doc' program of the 'Région Rhônes-Alpes', France. We especially want to thank the two reviewers Ernst Hauber and Lionel Wilson, as well as Hervé Bertrand and Janette Wilson, for their valuable advice. We are also really grateful to both the HiRISE and CRISM team for the availability of the data.

[15] The Editor thanks E. Hauber and Lionel Wilson for their assistance in evaluating this paper.

\section{References}

Burns, R. G. (1970), Crystal field spectra and evidence of cation ordering in olivine minerals, Am. Mineral., 55, 1608-1632.

Burns, R. G. (1974), The polarized spectra of iron in silicates: Olivine. A discussion of neglected contributions from $\mathrm{Fe}^{\prime *}$ ions in $\mathrm{M}(1)$ sites, $\mathrm{Am}$. Mineral., 59, 625-629.

Burns, R. G. (1993), Mineralogical Applications of Crystal Field Theory, 2nd ed., 551 pp., Cambridge Univ. Press, Cambridge, U. K., doi:10.1017/CBO9780511524899.

Carr, M. H. (1974), Tectonism and volcanism of Tharsis region of Mars, J. Geophys. Res., 79(26), 3943-3949, doi:10.1029/JB079i026p03943.

Carr, M. H., and J. W. Head III (2010), Geologic history of Mars, Earth Planet. Sci. Lett., 294(3-4), 185-203, doi:10.1016/j.epsl.2009.06.042.

Clenet, H., et al. (2011a), Compositional diversity of mafic rocks in the vicinity of Valles Marineris, Mars, using Modified Gaussian Model, Lunar Planet. Sci., XLII, Abstract 1674.

Clenet, H., et al. (2011b), A new systematic approach using the Modified Gaussian Model: Insight for the characterization of chemical composition of olivines, pyroxenes and olivine-pyroxene mixtures, Icarus, 213(1), 404-422, doi:10.1016/j.icarus.2011.03.002

Edwards, C. S., P. R. Christensen, and V. E. Hamilton (2008), Evidence for extensive olivine-rich basalt bedrock outcrops in Ganges and Eos chasmas, Mars, J. Geophys. Res., 113, E11003, doi:10.1029/2008JE003091.

Ehlmann, B. L., et al. (2009), Identification of hydrated silicate minerals on Mars using MRO-CRISM: Geologic context near Nili Fossae and implications for aqueous alteration, J. Geophys. Res., 114, E00D08, doi:10.1029/2009JE003339.

Ernst, R., E. Grosfils, and D. Mège (2001), Giant dike swarms: Earth, Venus, and Mars, Annu. Rev. Earth Planet. Sci., 29(1), 489-534, doi:10.1146/annurev.earth.29.1.489.

Flahaut, J., H. Clenet, J. F. Mustard, C. Quantin, and P. Allemand (2010a), Phyllosilicates and low calcium pyroxene-rich Noachian crust exposures in the walls of Valles Marineris, Mars, Lunar Planet. Sci., XLI, Abstract 1524.

Flahaut, J., C. Quantin, P. Allemand, P. Thomas, and L. Le Deit (2010b), Identification, distribution and possible origins of sulfates in Capri Chasma (Mars), inferred from CRISM data, J. Geophys. Res., 115, E11007, doi:10.1029/2009JE003566.

Hauber, E., M. Grott, and P. Kronberg (2010), Martian rifts: Structural geology and geophysics, Earth Planet. Sci. Lett., 294, 393-410, doi:10.1016/j.eps1.2009.11.005

Head, J. W., and L. Wilson (2002), Mars: A review and synthesis of general environments and geological settings of magma- $\mathrm{H}_{2} \mathrm{O}$ interactions, in 
Volcano-Ice Interactions on Earth and Mars, edited by J. L. Smellie and M. G. Chapman, Spec. Publ. Geol. Soc., 202, 27-57.

Head, J. W., L. Wilson, and K. L. Mitchell (2003), Generation of recent massive water floods at Cerberus Fossae, Mars by dike emplacement, cryospheric cracking, and confined aquifer groundwater release, Geophys. Res. Lett., 30(11), 1577, doi:10.1029/2003GL017135.

Kanner, L. C., J. F. Mustard, and A. Gendrin (2007), Assessing the limits of the Modified Gaussian Model for remote spectroscopic studies of pyroxenes on Mars, Icarus, 187(2), 442-456, doi:10.1016/j.icarus.2006.10.025.

Korteniemi, J., J. Raitala, M. Aittola, M. A. Ivanov, V.-P. Kostama, T. Öhman, and H. Hiesinger (2010), Dike indicators in the Hadriaca Patera-Promethei Terra region, Mars, Earth Planet. Sci. Lett., 294(3-4), 466-478, doi:10.1016/j.epsl.2009.06.038.

Mastin, L. G., and D. D. Pollard (1988), Surface deformation and shallow dike intrusion processes at Inyo Craters, Long Valley, California, J. Geophys Res., 93(B11), 13,221-13,235, doi:10.1029/JB093iB11p13221.

McEwen, A. S., M. C. Malin, M. H. Carr, and W. K. Hartmann (1999), Voluminous volcanism on early Mars revealed in Valles Marineris, Nature, 397(6720), 584-586, doi:10.1038/17539.

McEwen, A. S., et al. (2007), Mars Reconnaissance Orbiter's High Resolution Imaging Science Experiment (HiRISE), J. Geophys. Res., 112 E05S02, doi:10.1029/2005JE002605.

McKenzie, D., and F. Nimmo (1999), The generation of Martian floods by the melting of ground ice above dykes, Nature, 397(6716), 231-233, doi:10.1038/16649.

Mège, D., and P. Masson (1996), A plume tectonics model for the Tharsis province, Mars, Planet. Space Sci., 44(12), 1499-1546, doi:10.1016 S0032-0633(96)00113-4.

Mège, D., A. C. Cook, E. Garel, Y. Lagabrielle, and M.-H. Cormier (2003), Volcanic rifting at Martian grabens, J. Geophys. Res., 108(E5), 5044, doi:10.1029/2002JE001852.

Murchie, S., et al. (2007), Compact reconnaissance Imaging Spectrometer for Mars (CRISM) on Mars Reconnaissance Orbiter (MRO), J. Geophys. Res., 112, E05S03, doi:10.1029/2006JE002682.

Mustard, J. F., F. Poulet, A. Gendrin, J. P. Bibring, Y. Langevin, B. Gondet, N. Mangold, G. Bellucci, and F. Altieri (2005), Olivine and pyroxene, diversity in the crust of Mars, Science, 307(5715), 1594-1597, doi:10.1126/science.1109098.
Mustard, J. F., B. L. Ehlmann, S. L. Murchie, F. Poulet, N. Mangold, J. W. Head, J. P. Bibring, and L. H. Roach (2009), Composition, morphology, and stratigraphy of Noachian crust around the Isidis basin, J. Geophys. Res., 114, E00D12, doi:10.1029/2009JE003349.

Pedersen, G. B. M., J. W. Head, and L. Wilson (2010), Formation, erosion and exposure of Early Amazonian dikes, dike swarms and possible subglacial eruptions in the Elysium Rise/Utopia Basin Region, Mars, Earth Planet. Sci. Lett., 294(3-4), 424-439, doi:10.1016/j.eps1.2009.08.010.

Pelkey, S. M., et al. (2007), CRISM multispectral summary products Parameterizing mineral diversity on Mars from reflectance, J. Geophys. Res., 112, E08S14, doi:10.1029/2006JE002831.

Poulet, F., et al. (2009), Quantitative compositional analysis of Martian mafic regions using the Mex/OMEGA reflectance data: 1. Methodology, uncertainties and examples of application, Icarus, 201, 69-83, doi:10.1016/j.icarus.2008.12.025.

Quantin, C., J. Flahaut, and P. Allemand (2009), Buried layers beneath south rim of Valles Marineris revealed by central uplift of impact craters, Lunar Planet. Sci., XL, Abstract 1651.

Salvatore, M. R., J. F. Mustard, M. B. Wyatt, and S. L. Murchie (2010), Definitive evidence of Hesperian basalt in Acidalia and Chryse planitiae, J. Geophys. Res., 115, E07005, doi:10.1029/2009JE003519.

Schultz, R. A., C. H. Okubo, C. L. Goudy, and S. J. Wilkins (2004), Igneous dikes on Mars revealed by Mars Orbiter Laser Altimeter topography, Geology, 32(10), 889-892, doi:10.1130/G20548.1.

Skok, J. R., et al. (2009), Identification of primary Noachian crustal blocks on Mars with CRISM observations, Lunar Planet. Sci., XL, Abstract 2180.

Skok, J. R., J. F. Mustard, S. L. Murchie, M. B. Wyatt, and B. L. Ehlmann (2010), Spectrally distinct ejecta in Syrtis Major, Mars: Evidence for environmental change at the Hesperian-Amazonian boundary, J. Geophys. Res., 115, E00D14, doi:10.1029/2009JE003338.

P. Allemand, H. Clenet, J. Flahaut, C. Quantin, and P. Thomas, Laboratoire de Géologie de Lyon, UMR 5276, CNRS, Ecole Normale Supérieure de Lyon, Université Lyon 1, 2, rue Raphael Dubois, F-69622 Villeurbanne CEDEX, France. (jessica.flahaut@ens-lyon.org)

J. F. Mustard, Department of Geological Sciences, Brown University, Box 1846, 324 Brook St., Providence, RI 02912, USA. 